\title{
Adaptive Training System Model to Improve the Information and Communication Technology Skills of Personnel, Thailand
}

\author{
Phimchanok Khamchai, Khwanying Sriprasertpap, and Rittichai On-ming
}

\begin{abstract}
The objective of the research is to improve an adaptive training system and to study the using model. The present technology is used to support the training and adapt the training content to trainees based on their individual learning abilities. This is quantitative research which sample group is purposive sampling. The adaptive training uses technology called web-based training to create the system that trainees can be self-directed learning and also be on the job training. This advanced technology makes high quality learning at an affordable price. The improvement and finding quality of an adaptive training system for developing information technology and communication's skill in the research is found that 1) the overall quality of an adaptive training system for developing information technology and communication's skill to personnel at Srinakharinwirot University is high which mean $=4.75$ and S.D. = 0.33. 2) The post-test score of the trainees is higher than the pre-test score with statistical significance at 0.05 .
\end{abstract}

Index Terms-Adaptive learning, adaptive training, online training.

\section{INTRODUCTION}

Srinakharinwirot University places importance on personnel knowledge and ability improvement. Students from the university also have necessary skills on digital technology. The improvement model is that all departments can manage their knowledge and share it with each other through technology training courses. This can be applied to management projects in university service with digital technology [1]. However, the research "Knowledge management for operation personnel in knowledge management and application" [2] finds that most personnel at Srinakharinwirot University prefers training for developing their overall skill with different courses depending on their level of education, work experience, performance status and job description. The university should provide documents, handbooks, texts and new academic journals to their personnel so they can self-directed learning, develop their knowledge and have positive working attitudes. The training content should be adaptive to learners based on individual learning ability because of their different perceived skills. Flexible tests can be used to match individual trainees' expertise and differentiation.

Manuscript received June 29, 2021; revised September 13, 2021

Phimchanok Khamchai is with CEMT, Srinakharinwirot University, Bangkok, Thailand (e-mail: Phimchanok.khamchai@g.swu.ac.th).

Khwanying Sriprasertpap and Rittichai On-ming are with Technology Education Department, Faculty of Education, Srinakharinwirot University, Bangkok, Thailand (e-mail: khwanying@g.swu.ac.th, ritticha@g.swu.ac.th).
Nowadays, the difference in the level of trainee knowledge has often challenged the instructor [3]. Adaptive feedback information is supported in computer learning environments which can respond to different trainees. It is likely to be more prevalent [4]. The prevalence of COVID-19 has a severe effect on the education system. The learning activities have changed from traditional learning to remote learning. Using ICT is the best choice to avoid the failure of the worldwide education system [5]. In Thailand, teachers have to adapt their teaching way to a new normal which is work from home via electronic system. Teachers are required to prepare their work system and online system so that the workflow of the government agencies can be operated continuously. In the present time, the work system of government agencies is using digital and electronic such as e-document, e-meeting and e-conference via Zoom [6].

The improvement of personnel which is part of organization development has to adapt their way to be in accordance with the present circumstances. Using technology as a core of training is a good option. In addition, online training allows trainee to take self-guided learning by using technology in their daily life such as message broad on social media and other online communication way. All tools are combined for online learning. With technology, the learning course is always up-to-date which is necessary for improving people to be more effective as their department required. This method also saves time, resource and cost for their department. In addition, personnel can be in-service training. Online learning forces trainees to have self-discipline to a level that they can plan their learning, study time and how to repeat the content. Therefore, e-learning technology contributes skill development for trainee in learning process management [7].

The mechanism of an adaptive training system is to advice or bring a lesson from trainee's decision what they want for the next session by considering from present trainee database in order to forecast the characteristics of the trainees [8]. It also conforms with Alameen [9] who presents five steps of an adaptive module which are 1) analyze trainees' demand 2) prepare the learning source 3) record activities and behavior of trainees for analyzing trainees' progress 4) evaluate trainee's activities and 5) feedback all information to trainees.

From above reason, researcher has created the model for developing an adaptive training system to improve information technology and communication skill of operation personnel at Srinakharinwirot University by using the online training. Technological mechanisms for assessing trainee's ability can choose a lesson or learning method that is 
most beneficial to the aptitude learning process. The result of the research is a knowledge management system tool that guides the improvement of other training to evolve personnel to be self-directed learning. The university will be benefited in terms of human resource improvement that expects personnel to have necessary competencies in digital technology to boost up their learning and operation. In addition, the model of developing an adaptive training system can be in-service training and on the job training. Trainees have no need to leave their work for training. It is time, resource and cost saving for the organization. It is also a guideline for enhancing the potential of personnel.

\section{Problem And ObJective}

The problems are of the following:

1) To improve an adaptive training system in order to enhance information technology and communication skills of operation personnel at Srinakharinwirot University.

2) To study the result of adaptive training.

The encouragement of human resource development must take these factors into account. Thus, the researcher has created the model to find an appropriate training method for trainees. Trainees can learn according to their own needs.

\section{Methodology}

The method of the research and the data collection tools consists of an adaptive training course for enhancing information technology and communication skill, an adaptive training system and index of item objective congruence assessment form. There are two sample groups in the research. The first group is three online education specialists. The second group is 19 operational personnel from the Center for Educational Media and Technology department at Srinakharinwirot University who voluntarily participate in adaptive training. All personnel in the second group have a basic information technology skill. Their age is between 22 to 57 years old. Their background education consists of 14 personnel with Bachelor's degree, 4 personnel with Master's degrees and 1 personnel with Ph.D.

The first step is to study and analyze basic problems and demand in human resource development. Then, a training course and online adaptive training system is designed. The three education specialists assess index of item objective congruence (IOC) of course structure, online lesson and website. Then, they evaluate the quality of an adaptive training system by using five levels of rating scale.

The second step is to study the result of the adaptive training system before the actual trial. The second sample group registers on an online adaptive training website. Then, using tools for data collection and analyzing data by finding mean, standard deviation value and one sample t-test.

Tools used in the research are as the following:

1) An adaptive training course to enhance information technology and communication skill.

2) Index of item objective congruence (IOC) of course structure, online lesson and website.
3) Pre-test and post-test of an adaptive training about information technology and communication skill with Microsoft Word topic.

4) The assessment form of IOC of pre-test and post-test of an adaptive training with Microsoft Word topic. (The IOC with the lowest value is 0.33 and the highest value is 1.)

5) An adaptive training system to enhance information technology and communication skill.

6) A quality assessment form of an adaptive training system to enhance information technology and communication skill. $($ Mean $=4.75)$

\section{RESUlts}

\section{A. Adaptive Training Model}

Researcher has designed an adaptive training system that allows trainees to lead themselves in online learning and practice through a training website. The course includes content and training activities according to the knowledge level in a form of interaction on the learning aptitude of the trainees. Pre-test is used for analyzing the learning needs. It is an important step for self-directed learning. There is no best method. A variety of methods must be used to identify various needs [10]. When trainees study all content in the course and all activities suggested by the system, trainees will have a right to do the post-test and have to score more than $80 \%$ to get a certificate as in Fig. 1. In conformity with adaptation module 5 steps by Alameen [9], which are 1) analyze trainees' demand 2) prepare the learning source 3) record activities and behavior of trainees for analyzing trainees' progress 4) evaluate trainee's activities and 5) feedback all information to trainees. Their prominent point is a management of learning options that are consistent with trainees by using a learning management system. Instructors or system administrators can monitor trainee progress. When the system detects a change, it can redirect the user to a new learning path by presenting an adaptive lesson and continue the same process again. This process is recorded over and over until the course has been completed.

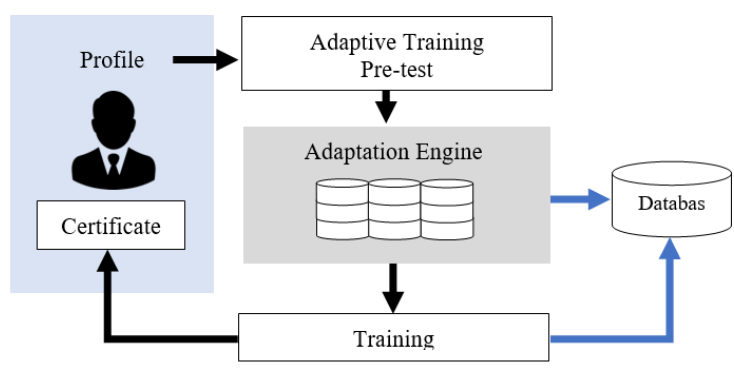

Fig. 1. Adaptive training model.

The process of assessing the competence of the trainees includes three main elements as in Fig. 2.

Assessment of trainee competence consists three parts which are of the following;

1) Input: pre-test using the exam to measure the knowledge level of the trainees to know the aptitude or prior knowledge of each trainee.

2) Process: for the evaluation, the score criteria from the 
adaptive training course is used including two systems which are of the following;

- The exam scoring

- Predictive learning abilities by dividing the scores according to the learning objectives. There are 27 patterns of adaptive content for trainees. These patterns are created by the adaptation engine according to the course structure. The number of behaviors that occur can be calculated by the formula $\left(\mathrm{n}_{1} \times \mathrm{n}_{2} \times \mathrm{n}_{3}, \ldots, \mathrm{n}_{\mathrm{k}}\right)$ as shown in Fig. 3 .

3) Output; the three lessons that are appropriate to trainees' ability.

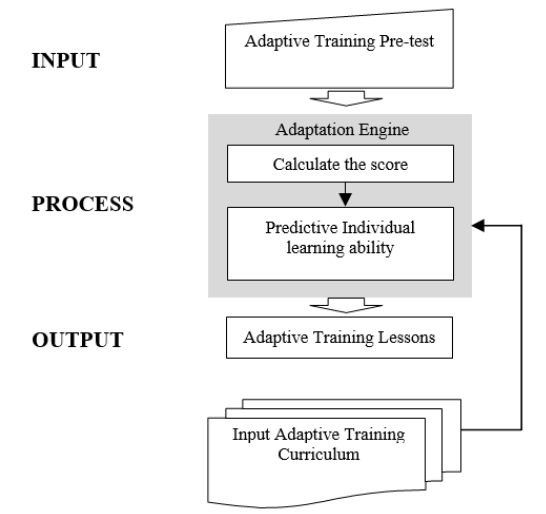

Fig. 2. Assessment of trainee competence.

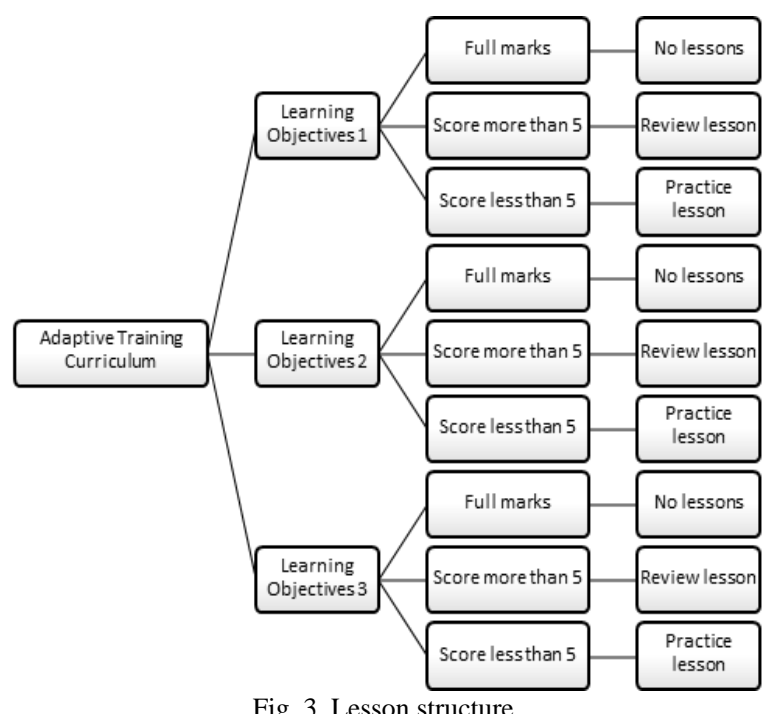

Fig. 3. Lesson structure.

An adaptive learning processes include three main parts as in Fig. 4.

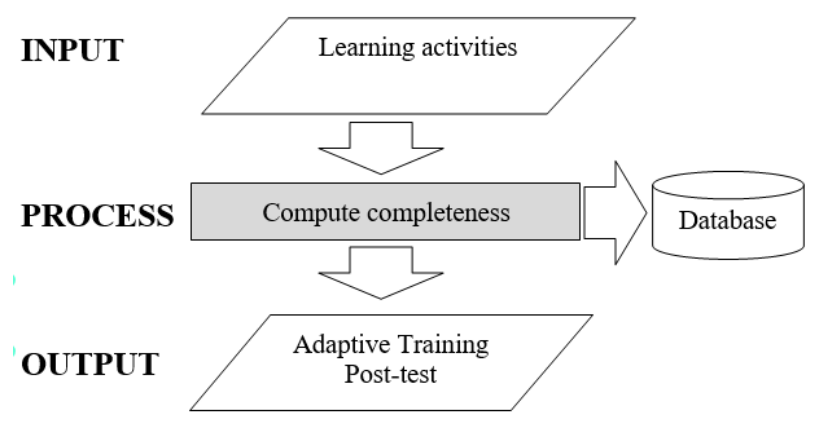

Fig. 4. An adaptive learning processes.

An adaptive training model consists three parts which are of the following:
1) Input: learning information of trainee and the activities in three lessons which are presented by an adaptive training system.

2) Process: the system will check the completeness of the study in the evaluation step such as activities in the lesson and assignment. If completed, the system will allow trainees to do an adaptive training post-test.

3) Output: post-test for trainees who complete the study. When trainees finish the post-test, the system will keep the data to the database so the system administrator can recheck before sending a certificate to trainees.

\section{B. Adaptive Training Website}

This step is to design a sitemap and UI for an adaptive training website to align work processes with an adaptive training model. The model has already obtained the quality of training courses and adaptive training systems from three online education specialists and the evaluation of applicable media by three personnel from the Center for Educational Media and Technology department. The researcher uses WordPress platform to create the website and chooses Plugin which is public and free to design the workflow to send and receive information automatically. Therefore, an adaptive training system can operate on its own without any operator except contacting for support. Site map is in Fig. 5.

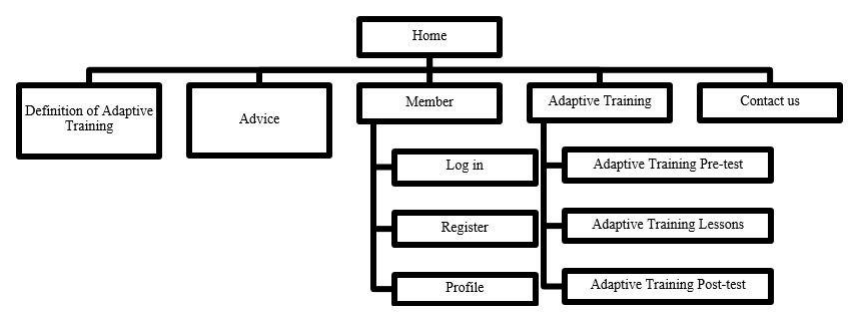

Fig. 5. Site map.

Experts' quality assessment of an adaptive training system for the development of personnel's information technology and communication skills at Srinakharinwirot University. The researcher created an adaptive training website and assessed the effectiveness of an adaptive training system in order to improve personnel's information technology and communication skills at Srinakharinwirot University. It was discovered that it was in a very excellent level after reviewing the data from the evaluation of three specialists. Table I shows that the mean was 4.75 and the standard deviation was 0.33 .

TABLE I: THE EVALUATE RESUlt OF QUALITY OF AN ADAPTIVE TRAINING SYSTEM FOR DEVELOPING INFORMATION TECHNOLOGY AND COMMUNICATION'S SKILL TO PERSONNEL AT SRINAKHARINWIROT

\begin{tabular}{lccc}
\multicolumn{4}{c}{ UNIVERSITY } \\
\hline \hline Mean & S.D. & Quality level \\
\hline Course management & 4.81 & 0.25 & Very good \\
\hline Learning system design & 4.78 & 0.29 & Very good \\
\hline Alphabet appearance & 4.83 & 0.15 & Very good \\
\hline Language & 4.78 & 0.39 & Very good \\
\hline Graphic design & 4.67 & 0.39 & Very good \\
\hline Sound effect & 4.60 & 0.46 & Very good \\
\hline Interaction and link & 4.80 & 0.35 & Very good \\
\hline Mean & $\mathbf{4 . 7 5}$ & $\mathbf{0 . 3 3}$ & Very good \\
\hline \hline
\end{tabular}

Fig. 6 shows the homepage which main menu is designed on the top and appears on every page. The content describes 
the meaning of adaptive training to trainees. There is a button to start adaptive training. When it is clicked, the ongoing training course will be shown. Tab bar with icon and short explanation is to catch the 4 steps of an adaptive training which are 1) Pre-test 2) Study following the display lesson 3) Post-test and 4) Certificate. The next content is an ongoing adaptive training curriculum. As a system trial, researchers have developed 1 course to study the results of an adaptive training system before the actual trial.

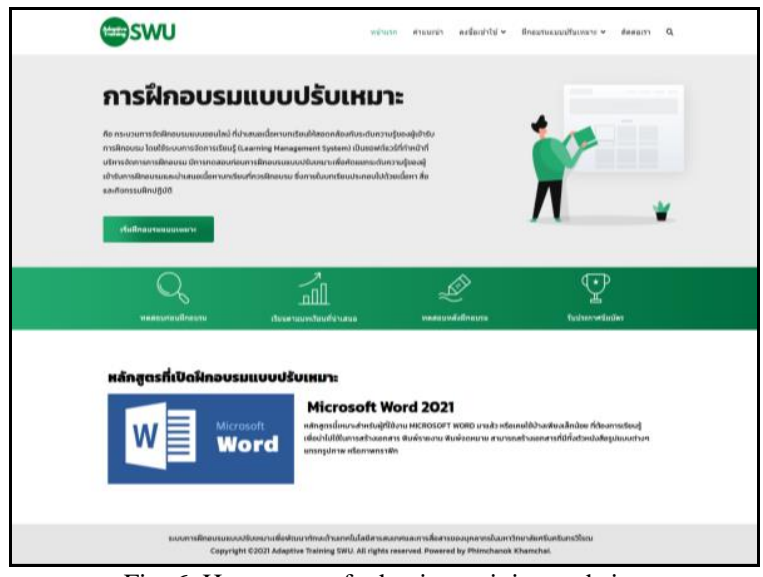

Fig. 6. Homepage of adaptive training website.

Instruction (Fig. 7) and contact us page (Fig. 8) are a communication module to support website and guideline users. Although self-directed learning is easy for adults, there must also be a framework that is easy to understand [11]. When users face a problem or need some help, they can contact the developer to continue self-adaptive training. The module is used to send and receive messages from trainees through UI intermediaries.

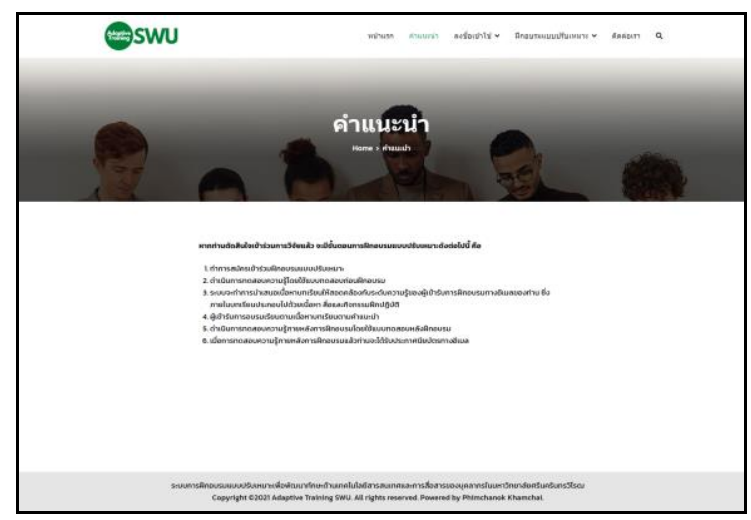

Fig. 7. Instruction page.

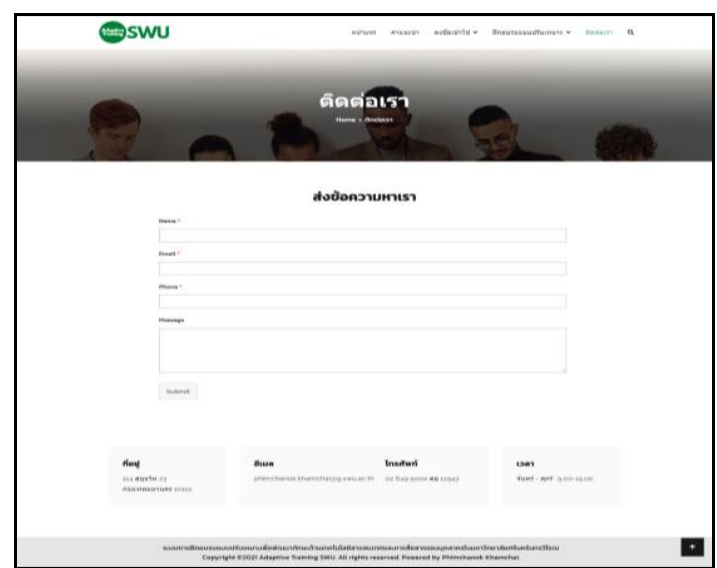

Fig. 8. Contact us page.
Pre-test page (Fig. 9) is the input part of the process of assessing the competence of the trainees. It is used to evaluate the knowledge level of a trainee and calculate the result by two steps which are 1) Scoring the exam and keeping it in the database to study and compare with the outcome. 2) Predictive learning abilities which is the main part of an adaptive learning and can offer lessons that are suitable for trainees' ability. The main objective of adaptive learning is to help trainees get the knowledge they need which is not to bring knowledge to the trainee. There are a variety of methods of adaptive learning. Profile optimization is one method but it is not enough if the needs of the organization are not taken into account [12]. Combining the needs of both parties will lead to success in the learning process.

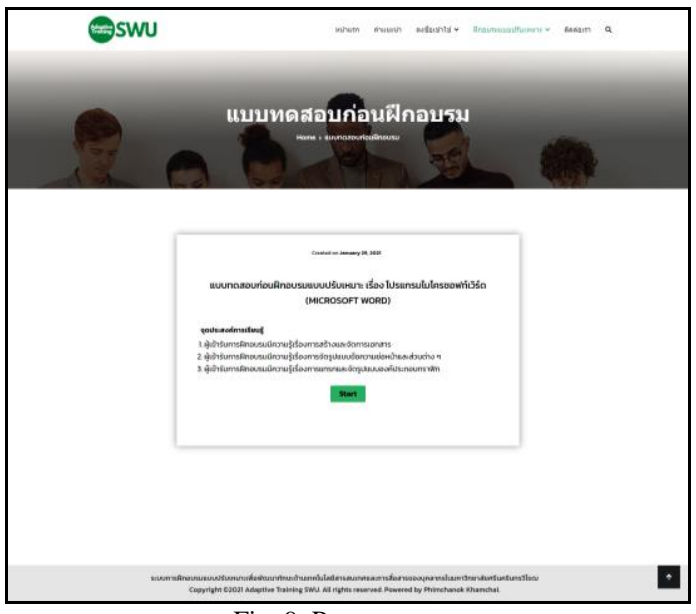

Fig. 9. Pre-test page.

Lesson page (Fig. 10) is part of the process of an adaptive learning. It is a lesson foreground in each learning objective. Trainees can do learning activities here and the system can track their access and assignment. Trainees can choose which lesson they want to learn first. When all lessons are completed, the system will allow trainees to do post-test.

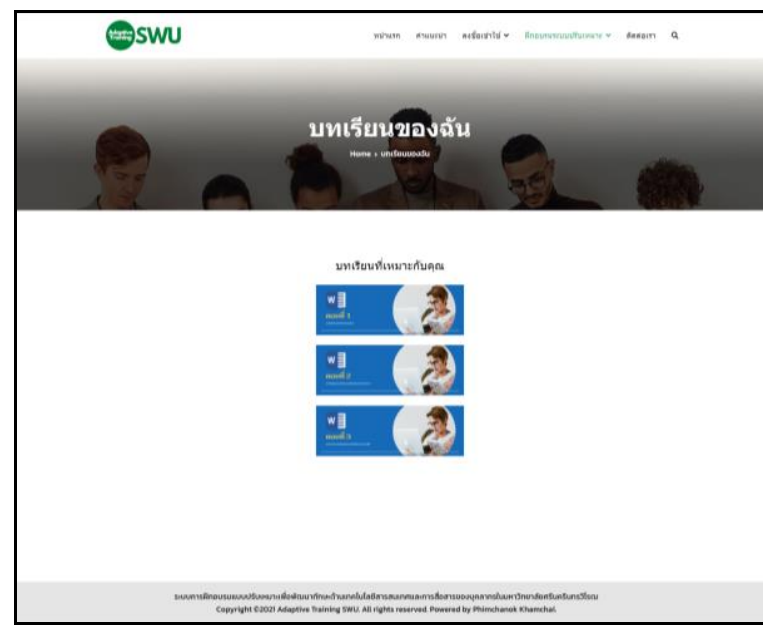

Fig. 10. Lesson page.

For post-test (Fig. 11), trainees can do it after they finish all activities an adaptive system has suggested. If they pass the post-test, they will get a certificate via Email they have registered. If they don't pass the post-test, they can repeat their lessons and do the post-test again. 


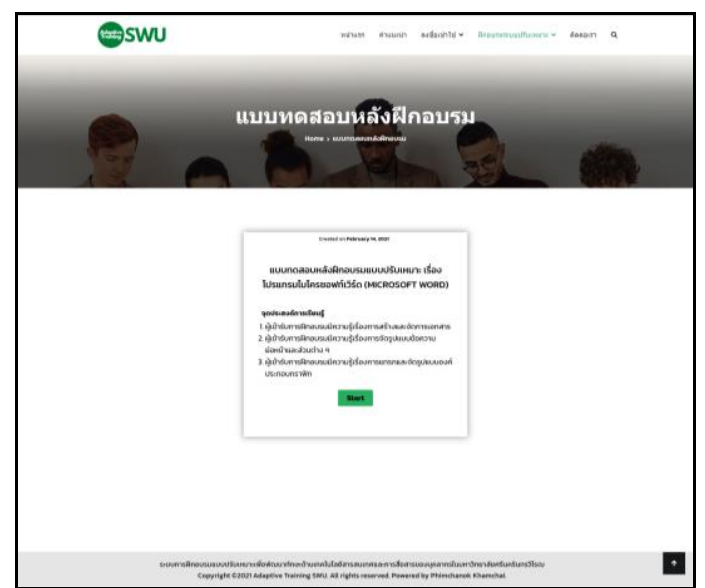

Fig. 11. Post-test page.

\section{The Result of Using An AdAPtive Training System}

The researcher designs a post-test of adaptive training about information technology and communication's skill with the topic of "Microsoft Word". The post-test includes 30 questions to determine the statistical difference of scores before and after training. The obtained scores are used to test the hypothesis by using dependent t-test. The results are shown in Table II.

TABLE II: THE COMPARISON OF SCORES FROM PRE-TRAINING TESTS AND POST-TRAINING TESTS

\begin{tabular}{ccccccc}
\hline \hline Test & Full Score & $\mathrm{N}$ & Mean & S.D. & t-test & p-value \\
\hline Pre-test & 30 & 19 & 19.16 & 4.37 & \multirow{2}{*}{7.55} & \multirow{2}{*}{0.000} \\
\hline Post-test & 30 & 19 & 25.16 & 1.54 & & \\
\hline \hline & $* 00.05$.
\end{tabular}

As seen in Table II, the trainees who using an adaptive training system to improve information technology and communication skill of operation personnel at Srinakharinwirot University have the average score of pre-test equal to 19.16 , S.D. is 4.37 and the average score of post-test equal to 25.16 , S.D. is 1.54 . It can be concluded that it is in accordance with the hypothesis which is trainees who using an adaptive training system to improve information technology and communication skill of operation personnel at Srinakharinwirot University have higher information technology and communication skills than before with statistical significance at 0.05 .

\section{DISCUSSION AND CONCLUSION}

An adaptive training model is created by the WordPress platform which is free. However, it is necessary to learn the new functionality of the available Plugin which takes some time but is worthwhile and saves cost. The model is suitable for a small group of people because the free platform limits the number of users per day. The training period needs to be adjusted to reduce the intensity of the user. The period may be divided into monthly or quarterly training for each department to provide training to cover the entire organization. It is a guideline to develop an online adaptive training for in-service training and on the job training. Technology is an engine to reduce a complicated procedure, fasten data transmission and to reduce production costs to increase efficiency and accuracy. To keep up with the changes and advancements of the digital age, whether in information services, communication, public relations, problem solving and operational planning, personnel should have information technology and communication's skill in order to share information and support the management of executives and organizations [13].

The improvement of an adaptive training system is for developing information technology and communication's skill of personnel at Srinakharinwirot University. It consists of five steps which are 1) Study and analyze basic information about problem and development needs 2) Design training course including content, media and activity 3) Find quality of an adaptive training course (IOC) 4) Improve and find quality of an adaptive training system 5) Study the result of an adaptive training method.

In the second phase, researchers choose 19 personnel from the Center for Educational Media and Technology department to be a sample group. The researcher will explain the objective of the research and the method of experiment through an adaptive training system. The sample group can carry out activities according to the training course for 2 weeks during May, 2021. It can be found that trainees who using an adaptive training system to improve information technology and communication skill of operation personnel at Srinakharinwirot University have higher information technology and communication skills than before with statistical significance at 0.05 .

In addition, researchers found that online training can be taken at the time that suits the trainees, depending on their availability and comfort. The time required to learn is reduced when compared to time required in traditional learning. Trainees can also access the content an unlimited number of times. Thus, adaptive training can be linked to various resources in several varying formats. It can meet the different demands of the trainees and helps the training to achieve its objectives very well. The training tracking shows that trainees who study practice lessons tend to access websites 2-3 times in one learning objective. Trainees who study review lessons tend to access websites 2 times in one learning objective. The trainees who study practice lessons take more time spent on the website than trainees who study review lessons about 6-10 minutes because these two lessons differ in terms of learning duration and exercise activities in each lesson. Another possible reason is trainees keep the training website page open. Thus, the website management service system can't indicate whether trainees still focus on the website. Although the both trainees take different learning duration, the score from exercise activities evaluated by Rubrics Score shows that the mean of them is not different.

\section{CONFLICT OF INTEREST}

The authors declare no conflict of interest.

\section{AUTHOR CONTRIBUTIONS}

K. P. did a literature review; defined the methodology research; data analysis and conclusions. K. P. having written the entire document. S. K. is advisor and O. R. is co-advisor for the research. All authors had approved the final version. 


\section{REFERENCES}

[1] (2018). Srinakharinwirot University, SWU ICT Master Plan 2017-2020. Reading, Bangkok: P and P Printing Prepress. [Online]. Available:

https://edocument.swu.ac.th/general/5900/pdf/1195900201800101.pdf

[2] S. Udomporn and P. Kesornphaet, "The study of knowledge management of academic infrastructure, Srinakharinwirot University," M.S. thesis, Srinakharinwirot University, Bangkok, Thailand, 2015.

[3] R. Luckin, W. Holmes, M. Griffiths, Mark, and B. Laurie, "Intelligence unleashed: An argument for AI in education," Pearson Education, London: Pearson Education, 2010.

[4] S. Narciss et al., "Exploring feedback and student characteristics relevant for personalizing feedback strategies," Computers \& Education, vol. 71, pp. 56-76, 2014.

[5] B. Singh, M. Palit, N. B. Thimmaiah, R. Gupta, and D. G Chowdhry, "Transformational learning: A comparative view in pre and post covid phase," Psychology and Education Journal, vol. 57, no. 9, 2020.

[6] S. Chaleoykitti, J. Artsanthia, and M. S. Daodee, "The effect of COVID-19 disease: Teaching and learning in nursing," Journal of Health and Nursing Research (Journal of Boromarajonani College of Nursing, Bangkok), vol. 36, no. 2, pp. 255-262, 2020.

[7] U. I. Nazarchuk, "Online training as alternative to classical training," Scientific Newsletter of Voronezh State University of Architecture \& Civil Engineering, vol. 25, no. 2, pp. 63-71, 2019.

[8] Y. Chen, X. Li, J. Liu, and Z. Ying, "Recommendation system for adaptive learning," Applied Psychological Measurement, vol. 42, no. 1, pp. 24-41, 2017.

[9] A. Alameen and B. Dhupia, "Implementing adaptive e-learning conceptual model: A survey and comparison with open source LMS," International Journal of Emerging Technologies in Learning (iJET), vol. 14 , no. $21,2019$.

[10] K. Walsh, "Self-directed learning at the point of care," InnovAiT, vol. 10 , no. 3, pp. 178-182, 2017.

[11] R. Hays, "Adult self-directed learning: setting your own agenda," InnovAiT, vol. 2, no. 7, pp. 434-438, 2009.

[12] A. Qodad, A. Benyoussef, A. El Kenz, and M. Elyadari, "Toward an adaptive educational hypermedia system (AEHS-JS) based on the overlay modeling and felder and silverman's learning styles model for job seekers," International Journal of Emerging Technologies in Learning (iJET), vol. 15, no. 08, 2020.

[13] C. Sukhum, T. chittima, and C. Witcha, Science Technology for Life, Bangkok: Suan Dusit University, 1999.

Copyright (C) 2022 by the authors. This is an open access article distributed under the Creative Commons Attribution License which permits unrestricted use, distribution, and reproduction in any medium, provided the original work is properly cited (CC BY 4.0).

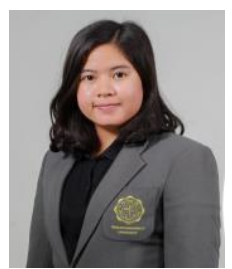

Phimchanok Khamchai is an educator at Srinakharinwirot University's Center for Educational Media and Technology in Bangkok, Thailand. She is interested and studied about learning management, active learning, and ICT management for teaching and learning systems.

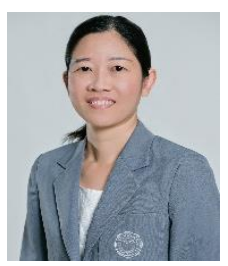

Khwanying Sriprasertpap is an assistant professor in the Department of Educational Technology, Srinakharinwirot University in Bangkok, Thailand. Presents she works in field of ICT in education. Her research topics and interests include instructional design, behavioral science, e-training, database development, ICT management, active learning and application for learning and management.

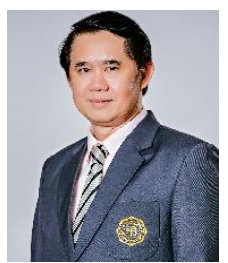

Rittichai On-ming is an assistant professor in the Department of Educational Technology, Srinakharinwirot University in Bangkok, Thailand. He specializes in medical education technology, television production, and learning resource management. 